\title{
Materiales especiales de la Guerra de la Independencia conservados en el Centro Documental de la Memoria Histórica (CDMH)
}

\author{
José-Tomás VELASCO SÁNCHEZ \\ (Universidad de Salamanca)
}

Resumen

Se da a conocer la existencia de un pequeño pero rico conjunto bibliográfico de la época de la Guerra de la Independencia depositado en el Archivo General de la Guerra Civil del Centro Documental de la Memoria Histórica. En él, se explica cómo pudo constituirse el conjunto bibliográfico, cómo pudo llegar a formar parte del Archivo de la Guerra Civil y qué tipo de materiales especiales bibliográficos lo conforman, libros y opúsculos, proclamas, manifiestos y exhortaciones, y sentencias judiciales, bandos e instrucciones militares, que dan lugar a las tres secciones en las que se divide este artículo. De cada una de estas obras, cuando es posible, se facilita, además de su título, lugar de impresión, año de impresión y tamaño, información sobre su autor, ediciones similares coetáneas y posteriores y las principales bibliotecas donde puede encontrarse otro ejemplar de la misma obra.

Palabras clave: Patrimonio bibliográfico español; Junta Central Gubernativa del Reino de España; Imprenta; Cádiz; Siglo XIX; Libros raros. 


\title{
Special Library Materials from the Spanish War of Independence (Peninsular War) Held in the Centro Documental de la Memoria Histórica $(\mathrm{CDMH})$
}

\begin{abstract}
This article provides information about a small collection of printed material from the period of the Spanish War of Independence deposited in the Archive of the Civil War of the Centro Documental de la Memoria Histórica (CDMH). It explains how the collection came into being, how it was incorporated into the Archive of the Civil War and what kind of special materials it consists of books and pamphlets; proclamations, manifestos and appeals; and sentences, military orders and instructions. The article is divided into three sections reflecting these holdings. As far as possible besides its title, place of printing, year of publication and format, each item is accompanied by information about its author, similar contemporary and later editions, and the main libraries where other copies of the same edition can be found.
\end{abstract}

Keywords: Spanish bibliographic heritage; Junta Central Gubernativa del Reino de España; Printing; $19^{\text {th }}$ century; Cadiz; Rare books.

\section{Introducción}

Los materiales especiales, dedicados cronológica y temáticamente a la Guerra de la Independencia, constituyen una original y rica rareza documental dentro de unas agrupaciones documentales, como las del Centro de la Memoria Histórica de Salamanca, dedicadas a la segunda República, la Guerra Civil, el franquismo y la transición democrática.

Dichos materiales especiales no se encuentran en el fondo antiguo originario incautado durante la guerra civil, como cabría esperar, fondo antiguo desafortunadamente mezclado físicamente con el fondo moderno formado a partir de las adquisiciones bibliográficas realizadas a partir de 1980 por la biblioteca del Centro, sino que forman parte del final de la serie Presidencia, cajas 109, 111 y 112, del fondo documental Delegación Nacional de Servicios Documentales del Archivo General de la Guerra Civil Española, y carecen de signatura topográfica.

Lo más probable es que, como producto de las incautaciones documentales realizadas por el equipos de recuperación de documentos franquistas, llegaran al Archivo de Salamanca, desde Cádiz, a través de Extremadura, y, muy posiblemente, formaron parte de la agrupación 
documental PS-Extremadura de la Sección Político-Social del Archivo de la cual fueron trasladados a su actual ubicación tanto física como dentro del cuadro de clasificación, la serie Presidencia.

Dentro de estos materiales especiales, encontramos libros y opúsculos, breves textos impresos no superiores, en la mayoría de los casos, a cuarenta y nueve páginas; proclamas, manifiestos y exhortaciones, breves textos impresos, de una o dos hojas de extensión, de carácter político para ser declamadas con la finalidad de informar y persuadir; y, finalmente, sentencias judiciales, bandos e instrucciones militares y papeles varios, estos últimos, manuscritos e impresos, cosidos, que han dado lugar a sendos volúmenes: el primero, del primer tercio del siglo XVIII y de 421 folios, que contiene documentos relacionados con la Guerra de Sucesión española y el reinado de Felipe V, de 1701 a 1717; y, el segundo, de 339 folios, un libro de actas municipales del Ayuntamiento de Tortosa, en el que se recoge la administración municipal llevada a cabo durante la ocupación francesa de la localidad tarraconense en la Guerra de la Independencia, y el posterior periodo de posguerra, de 1811 a 1818, y que debería transferirse al Arxin Comarcal del Baix Ebre, donde se halla depositado el Archivo Histórico Municipal de Tortora, en el que se encuentra la serie completa de libros de actas municipales.

La mayoría de estos textos fueron impresos en las ciudades de Madrid, Sevilla y Cádiz. A causa de la guerra, la Junta Suprema Central tuvo que trasladarse de Madrid a Sevilla y de Sevilla a Cádiz: allí, la Junta conoció y adquirió algunas de estas obras e impulsó otras, custodiando todas ellas con celo.

El periodo cronológico de impresión de estas obras abarca de 1701 a 1838, como fechas extremas, aunque se concentra en los años 1808 a 1814, durante los cuales se desarrolló el conflicto bélico.

La distribución geográfica, lugar de impresión, y cronológica, año de impresión, de las cuarenta y cuatro obras, de estos materiales especiales, dedicados a la Guerra de la Independencia, es la siguiente: 


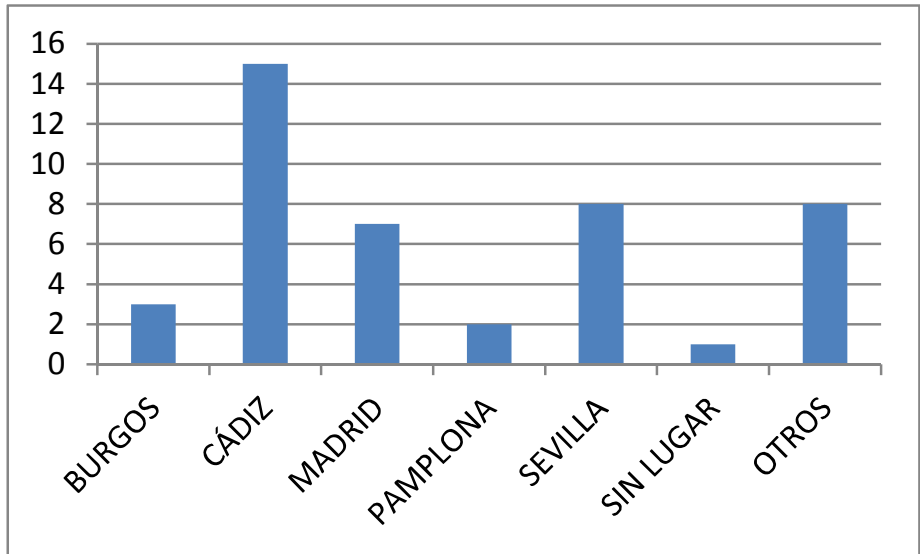

Gráfico 1: Lugar de impresión

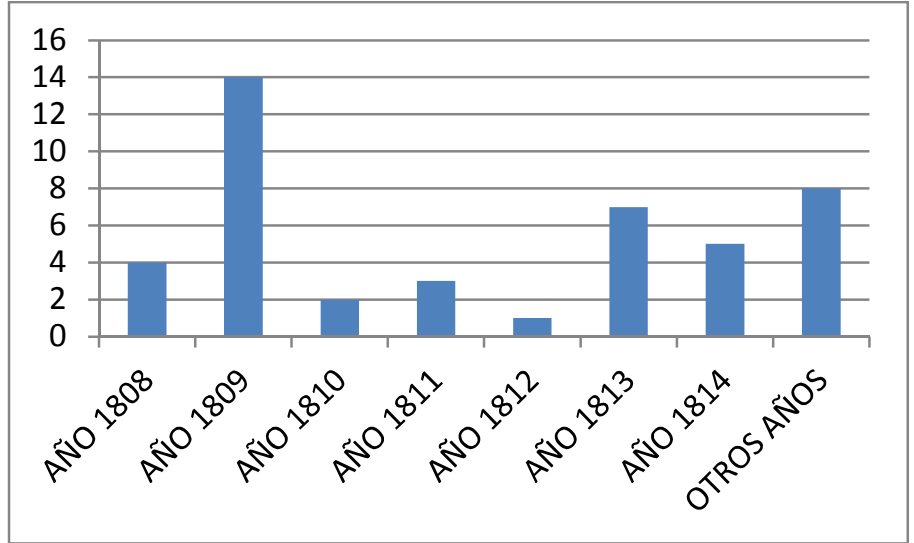

Gráfico 2.: Año de impresión

\section{Libros y opúsculos}

Los veinticuatro libros y opúsculos, que forman parte de los materiales especiales dedicados a la Guerra de la Independencia, conservados en el Archivo de la Guerra Civil del Centro Documental de la Memoria Histórica, fueron impresos entre 1799 y 1838, aunque, como se refleja en el gráfico anterior y como se expondrá a continuación, la mayoría fueron impresos entre 1808 y 1814.

De 1801, es el breve, que se conserva en el Archivo de la Guerra Civil, emitido por el papa Pío VI, de 48 páginas y tamaño folio, impreso con el extenso título Nos don Ramón Josef de Arce, por la gracia de Dios y de la Santa Sede Apostólica, Arzobispo de Burgos, del Consejo de S.M., Caballero de la Gran Cruz de la 
Real Orden de Carlos III, é Inquisidor general en todos los Reynos y Señoríos de S.M. a todos los Fieles habitantes ó moradores de ellos, de qualquier estado, calidad, órden ó dignidad que sean: Hacemos saber, que por nuestro Santisimo Padre Pio VI, de gloriosa memoria, manifestando su santo zelo por la pureza de la fe, pazy tranquilidad del pueblo christiano, se expidieron unas Letras en forma de Breve que S.M. el Señor Carlos IV (que Dios guarde), uniendo sus religiosas intenciones á las de S.B., se ha servido comunicarnos, y son del tenor siguiente. El encargado de dar difusión a esta obra fue Ramón José de Arce y Uribarri (Selaya, Cantabria, 1757-París, 1844), entonces arzobispo de Burgos, y que al poco tiempo sería nombrado arzobispo de Zaragoza, de 1801 a 1806, y último inquisidor general, de 1798 a 1808. Ramón José de Arce inició su carrera eclesiástica como colegial del Colegio Mayor de Cuenca de la Universidad de Salamanca. Afrancesado, y amigo personal de Manuel Godoy, juró fidelidad al rey José I Bonaparte. Con la restauración de Fernando VII en el trono, Ramón José de Arce tuvo que exiliarse, en 1814, a París, donde murió en 1844, siendo el único superior eclesiástico español que murió en el exilio. ${ }^{1}$

De 1808, es el breve epistolario en el que se hallan recogidas las cartas intercambiadas entre el general Francisco Javier Castaños, I duque de Bailén, y el general Gregorio García de la Cuesta, entonces Capitán General de Castilla, de 20 páginas de extensión, impreso en Sevilla, en la imprenta de la Viuda de Hidalgo y sobrino, titulado Correspondencia de los generales Castaños y Cuesta.

En 1809, auspiciadas por la Junta Suprema Central, aparecieron, en Sevilla, el Manifiesto de la nación española á la Europa, de 38 páginas y tamaño cuarto, y el opúsculo, de 22 páginas y tamaño cuarto, cuyo título, tomado del comienzo del texto, es Excelentísimo Señor: Despues de la defensa del Estado, que ha sido el primer objeto de las atenciones de la Junta Suprema, á nada se ha aplicado mas que á conservar la unión y la concordia entre las diversas partes que constituyen la Monarquia, y entre las diferenrtes autoridades que la dirigen y gobiernan. El Manifiesto, firmado, en la página 30, por Martín de Garay, como secretario general de la Junta Suprema, contiene, en las páginas 31 a 38, tres cartas intercambiadas entre los generales napoleónicos Murat y Dupont. De este texto, ese mismo año y con diferente extensión, existen otros ejemplares, realizados en Cádiz, en la imprenta de la Casa de la Misericordia; en Valencia, en la imprenta de la Viuda de Martín Peris; y, en Málaga, en la imprenta de Francisco Martínez de Aguilar. Por otra parte, hay que destacar que, del opúsculo de la Junta Suprema Central, dedicado a conservar la unidad de las autoridades en su acción de gobierno y de la monarquía, firmado, además de por Martín de Garay, como secretario general de la Junta Suprema, por Gaspar Melchor de Jovellanos, se conserva un ejemplar similar en la Biblioteca Nacional de España, cuya signatura topográfica es R/60880(1). En 1809, se publicó también el opúsculo titulado ¿Quál hubiera sido la suerte de España si Fernando VII no hubiera ido a Bayona? Papel, en que se manifiestan las justas causas que obligarian á nuestro Augusto Soberano á pasar

1 José María Calvo Fernández, Ramón José de Arce: Inquisidor general, arzobispo de Zaragoza y líder de los afrancesados, Zaragoza, Editorial Fundación Zaragoza 2008. 
á Bayona: bienes que de esto han resultado, y males que se han impedido, de 24 páginas y tamaño cuarto, publicado por la imprenta de la Gaceta de Murcia, del que existe otra impresión del año anterior, realizada en Madrid por el impresor Gómez Fuentenebro y que se vendía en la librería de Quiroga y Burguillos de la calle Carretas. La autoría de esta obra se atribuye a Manuel López Malo. De ese mismo año, es también la obrita titulada Gritos de Madrid cautivo á los pueblos de España. Nuevo género de esclavitud que prepara la bondad y amor paternal del Rey Josef á los pueblos que tengan la dicha de caer baxo su benéfica dominacion, de 16 páginas, publicada en Sevilla. De esta misma obrita, existe otra edición publicada en la imprenta Viuda de Peris de Valencia.

En 1811, se imprimió, en Cádiz, la obra titulada Representacion de las damas españolas a Jorge Tercero, Rei de Inglaterra, sobre los vagos rumores acerca de la conducta del Gobierno Ingles y de sus Exércitos en la Guerra de España, de 23 páginas y tamaño cuarto. De esta obra, existen tres ediciones y cuatro ejemplares en la Biblioteca Nacional de España: la primera, impresa en La Habana, en la Imprenta del Gobierno y Capitanía General, de 8 páginas, por lo que faltaría gran parte del texto, cuya signatura topográfica es HN/50270(8); la segunda, impresa en La Coruña, en la imprenta de Antonio Rodríguez, cuya signatura topográfica es VC/2714/28; y, la tercera, impresa en Valencia, en la imprenta de José Estévan, de 15 páginas, del se conservan dos ejemplares en la Biblioteca Nacional, cuyas signaturas topográficas son R/60362(30) y VC/808/37. En ese mismo año y en la imprenta de Manuel Boch, en Cádiz, apareció el libro titulado España vindicada, en sus clases y autoridades, de las falsas opiniones que se la atribuien, de 80 páginas y tamaño cuarto. Una segunda edición aumentada del libro, en la que se incluyen las censuras de la Junta Suprema y la Junta Provincial de Cádiz, fue publicada, tres años después, en Madrid, por la imprenta Repullés. Esta segunda edición tiene una extensión de 165 páginas. ${ }^{2}$ El autor de la obra, José Joaquín Colón de Larreátegui, cuando Aragón se encontraba ocupada por las tropas napoleónicas, fue elegido diputado en Cortes, las que se iban a celebrar en Cádiz, por la circunscripción electoral del Reino de Aragón, aunque tuvo que renunciar a su acta de diputado por no ser natural de Aragón, siendo sustituido por el diputado Ramón Ger. ${ }^{3}$

En 1813, se publicó, en la imprenta de Antonio de Murguía, en Cádiz, la Carta XXVIII del filósofo Rancio. Impugnación del informe que la Comisión de Constitución presentó a las Córtes sobre el Tribunal de la Inquisición y del proyecto del decreto acerca de los tribunales protectores de la religión, de 32 páginas y tamaño cuarto. En esta obra, su autor realiza una firme defensa de la Inquisición y, en sus Cartas, expone un proyecto de reforma para España conforme al ideario

2 Existe una edición facsímil de la obra, publicada por el Consejo Superior de Investigaciones Científicas en 2011, José Joaquín COLÓN DE LARREÁTEGUI, España vindicada, en sus clases y autoridades, de las falsas opiniones que se la atribuyen. Madrid, CSIC, 2011.

3 José Ramón de UrQuijo y GoITIA, «José Joaquín Colón y la rehabilitación de la monarquía absoluta», Revista de Historia Jerónimo Zurita, 87 (2012), pp. 171-206.

Titivillus, ISSN 2387-0915, ISSN-e 2603-9966, 4 (2018), pp. 165-180 
absolutista. El autor de estas Cartas, incluyendo la Carta XXVIII, es el fraile dominico Francisco Alvarado (Marchena, Sevilla, 1756-1814), que firmaba sus obras con el seudónimo de «filósofo Rancio». A los quince años, Francisco Alvarado ingresó en el Convento de San Pablo de Sevilla, donde estudió filosofía y teología. En 1810, tras la toma de Sevilla por las tropas napoleónicas, se exilió a Portugal, desde donde siguió los debates constituyentes de las Cortes de Cádiz, gracias a sus amigos, los diputados Francisco de Sales Rodríguez de la Bárcena, canónigo de la catedral de Sevilla y diputado por la circunscripción electoral de Sevilla, de septiembre de 1810 a julio de 1813, y Manuel Freire Castrillón, diputado por el Reino de Galicia, de noviembre de 1810 a julio de 1813, lo cual le permitió escribir su casi medio centenar de Cartas. ${ }^{4}$ La Carta XVIII se conserva en el Archivo de la Guerra Civil. De ese mismo año, es el Dictamen de las Comisiones encargadas de informar a las Cortes sobre el restablecimiento y reforma de las Casas Religiosas, mandado imprimir por orden de S.M., en Cádiz, en la Imprenta Nacional. De 79 páginas de extensión y tamaño cuarto, un ejemplar de este Dictamen, se conserva en la biblioteca de la Universidad de Princeton, cuya signatura antigua es RECAP 1526182866 y en la biblioteca general de la Universidad de Santiago de Compostela, cuya signatura topográfica es RSE.FOLL 33 4. También, en 1813, pero en la imprenta de Abadal, en Manresa, apareció la obra titulada La arbitrariedad é injusticia del odio de los filósofos de España á los Institutos Regulares, manifestadas al más justo y grande de los monarcas el Sr. D. Fernando VII, por el mas pequeño, pero el mas afecto de sus vasallos P.J.F.J.R., de 76 páginas y tamaño cuarto. Un ejemplar similar de esta obra se conserva en la biblioteca del Museo de Historia de Tarragona, según se indica en su Catálogo, editado en 2006.

En 1814, se publicó la sexta edición, en Madrid, en la imprenta de la Compañía, de la obra de Blas de Ostolaza y Ríos, Sermón patriótico-moral, que con motivo de una misa solemne, mandada celebrar el día 25 de julio del año 1810 en la iglesia de los RR.PP. Carmelitas de la ciudad de Cádiz. por los españoles emigrados de los países ocupados por el enemigo común, dixo por el doctor don Blas Ostolaza, diputado en Córtes, capellan de honor y confesor de S.M.C. El señor don Fernando Séptimo, rey de España y de sus Indias, y del señor infante don Carlos, de 64 páginas y tamaño cuarto. De esta obra, consevada en el Archivo de la Guerra Civil, existen tres ediciones anteriores: la de 1810, impresa por Manuel Santiago de Quintana, en Cádiz; la de 1811, impresa por Juan Vicente Teruel, en Murcia, reimpresión de la edición gaditana de la que se hizo cargo José Jiménez Sánchez, obispo de la diócesis de Cartagena-Murcia; y, la de 1812, impresa en la Oficina de Arévalo, en Nueva Guatemala. Al año siguiente, del mismo autor, fue publicado, también en Madrid, en la imprenta de Francisco Martínez Villa, el opúsculo titulado Los reos de Estado convencidos de haber conspirado á destruir el Gobierno monarquico en España, que da á luz.F.J.G.D.M.A.N., de 15 páginas y tamaño cuarto, también conservada en el Archivo de la Guerra Civil. Bajo este título,

4 Mario MÉndez Bejarano, «El siglo de las luces. Escolásticos rígidos. El P. Alvarado», Historia de la filosofía en España hasta el siglo XX, Madrid, Renacimiento, 1928. 
se publicó el sermón que Blas de Ostolaza pronunció, el 21 de diciembre de 1814, en la iglesia parroquial del antiguo convento de los Carmelitas, en la calle del Carmen, núm. 10, de Madrid, en el que realiza una defensa de la religión católica y de la monarquía, frente a aquellos que pretendían «republicanizar» España. Con este sermón, Blas de Ostolaza, deán de la catedral de Cartagena, y que había sido diputado en las Cortes de Cádiz por el Virreinato del Perú desde noviembre de 1810 hasta mayo de 1814, trata de dar respuesta a la obra de Francisco Martínez de la Rosa, La revolución actual de España, Madrid, Imprenta que fue de García, 1814. ${ }^{5}$ En el Archivo de la Guerra Civil, de ese mismo año 1814, se conserva la Canción que dedica y dirige a nuestro idolatrado soberano y Sr. D. Fernando VII uno de sus mas bumildes y fieles vasallos, tan amante de su patria, que por no faltar un momento al cumplimiento de las obligaciones de su destino militar en defensa de esta plaza, en sus tres asedios, sufrió en el ultimo tantas penalidades, que le produxeron la ruina de su salud, de 20 páginas de extensión y tamaño cuarto, publicada por la imprenta Francisco Brusola de Valencia. De esta pequeña obra, existe otro ejemplar similar, encuadernado, en la biblioteca de la Universidad de Navarra, cuya signatura topográfica es FA 260.502. ${ }^{6}$

Finalmente, en el Archivo de la Guerra Civil, se custodian dos de las primeras biografías dedicadas, respectivamente, al jurista y abogado de profesión, diputado por Asturias en las Cortes de Cádiz, de 1810 a 1813, y ponente constitucional, que participó en la redacción de la Constitución de 1812, y que llegaría a ser presidente del Congreso de los Diputados y preceptor de la futura reina Isabel II, Agustín Argüelles (Ribadesella, Asturias, 1776-Madrid, 1844), ${ }^{7}$ y, al héroe de la Guerra de la Independencia y militar Juan Martín «el Empecinado». ${ }^{8}$ La que puede ser considerada como la primera

${ }^{5}$ Fernán Altuve-Febrés Lores, «Blas de Ostolaza», Anales de la Fundación Francisco Elías de Tejada, 13 (2007), pp. 141-163.

6 A esta Canción, alude Gloria ROKISKI LÁZARO, en su Bibliografía de la poesía española del siglo XIX, 1801-1850. Obras generales. Autores y obras anónimas, Madrid, Consejo Superior de Investigaciones Científicas, 1988, p. 303, y María del Pilar SALAS Yus, en su obra Descripción bibliográfica de los textos literarios relativos a los Sitios de Zaragoza, Zaragoza, Institución Fernando el Católico, 2007, en la que la Canción aparece recogida.

${ }^{7}$ Sobre la figura de Agustín Argüelles, véanse las obras de Antonio RAMOS ArgüELLES, Agustin Argüelles, 1776-1844, padre del constitucionalismo español, Madrid, Atlas, 1990; Joaquín VARELA SuANZES-CARPEGNA, «Agustín Argüelles en la historia constitucional española», Revista Jurídica de Asturias, 20 (1996), pp. 7-24; y la antología de los discursos parlamentarios de Agustín Argüelles, compilada por el catedrático de Historia del Derecho de la Universidad de Salamanca y la UNED, Francisco TomÁs Y VALIENTE, bajo el título de Discursos de Agustín Argüelles, Oviedo, Junta General del Principado de Asturias, 1996.

8 Sobre la figura de Juan Martín «el Empecinado», véanse las obras de Florentino HeRnández Girbal, Juan Martín Diez, el Empecinado, terror de los franceses, Madrid, Lira, 1985, y el artículo de Javier IgLesia Berzosa, «Mito y realidad de Juan Martín Díez, el Empecinado. Nuevas aportaciones biográficas», La Guerra de la Independencia en el mosaico peninsular, Burgos, Universidad de Burgos, 2011, pp. 697-712.

Titivillus, ISSN 2387-0915, ISSN-e 2603-9966, 4 (2018), pp. 165-180 
biografía de Agustín Argüelles, verdadera hagiografía, conservada en el Archivo de la Guerra Civil, lleva por título Argüelles como es en sí: su sabiduría, su piedad, su verdadero amor á la Iglesia C.A.R... su todo contra los egoístas, déspotas, usurpadores (y añadamos por si acaso) y contra los ignorantes preocupados por F.M.G.N., de 40 páginas y tamaño cuarto, fue publicada, en Cádiz, en la imprenta de Vicente Lema. Por otra parte, la biografía de Juan Martín «el Empecinado» fue publicada, en Madrid, por la imprenta de Fermín Villalpando, con el título de Apuntes de la vida y hechos militares del brigadier don Juan Martín Diez, «el Empecinado", por un admirador de ellos, tamaño cuarto y 91 páginas de extensión. Sólo existe una obra anterior a ésta, la conservada en el Archivo de la Guerra Civil, dedicada a la figura de Juan Martín «el Empecinado»: se trata de la obra escrita por Francisco de Paula Alonso y Ruíz de Conejares titulada Resumen bistórico militar de los principales y mas gloriosos hechos del señor Brigadier Don Juan Martin, por sobrenombre el Empecinado, desde fines de Junio de mil ochocientos ocho hasta abril de ochocientos once, aparecida tres años antes, en 1811, en México, a cargo de la imprenta de Arizpe. Cronológicamente, la siguiente obra, tras la conservada en el Archivo, dedicada a la figura de Juan Martín «el Empecinado» sería, ya avanzado el siglo XIX, la novela histórica, que, dentro de los Episodios Nacionales, dedica Benito Pérez Galdós a Juan Martín «el Empecinado», cuya primera edición es del año 1874.

\section{Proclamas, manifiestos y exhortaciones}

En el Archivo de la Guerra Civil, se conservan, en total, catorce proclamas, manifiestos y exhortaciones de la Guerra de la Independencia, publicadas entre junio de 1808 y marzo de 1815.

En el Archivo, se conserva la Proclama de la Junta Suprema de Gobierno del Reino a los andaluces, en la que se da a conocer que el ejército napoleónico se acerca a Andalucía y se hace un llamamiento a la lucha contra el mismo. Que «cada andaluz sea un héroe, cada casa un fuerte, cada pueblo una ciudadela, y la Andalucía será la tumba de todo el exército Frances», se dice en la misma. De esta Proclama, sin fecha y tamaño folio, se conservan dieciocho ejemplares en la serie Manifiestos y proclamas de la Junta de la sección Junta Central Gubernativa del Reino del fondo Instituciones de Gobierno de la Monarquía del Antiguo Régimen del Archivo Histórico Nacional de España, cuya signatura topográfica es ES.28079.AHN/1.1.17/ESTADO, 13, F.

En el Archivo de la Guerra Civil, se conservan, también, las proclamas realizadas por el emperador Francisco I de Austria y su hermano el archiduque Carlos de Austria. En la Proclama de S.M. Imperial Francisco I, por la gracia de Dios, emperador de Austria, hecha en Viena el 18 de abril de 1809, el emperador Francisco I comunica a su pueblo que, debido a la situación militar, se ve obligado a abandonar Viena. De Napoleón dice que, además de intentar someter al Imperio austrohúngaro, «se esfuerza á subyugar la España, [e] insulta la Cabeza sagrada de la Iglesia; se hace dueño de las Provincias de Italia; y reparte los dominios de Alemania». Esta Proclama de S.M. Imperial Francisco I, 
fue impresa en Cádiz, a gran formato o formato sábana, ya que fue traducida al español del periódico escocés The Courier, en el que había sido publicada el 1 de mayo de 1809. Por su parte, en la Proclama del Archiduque Carlos de Austria, hecha en Viena el 6 de abril de 1809, el archiduque Carlos de Austria defiende la independencia del Imperio austrohúngaro frente a la «insaciable ambición de un conquistador extranjero», Napoleón, al que califica de «advenedizo á un trono usurpado por cima de los cadáveres de los defensores de su Patria». Asimismo, recuerda a los soldados austríacos, como comandante en jefe del ejército austríaco que era contra el ejército napoleónico, que «no deben serle agenas las virtudes cívicas. Fuera del campo de batalla para con el ciudadano desarmado, para con el aldeano, siempre ha de ser humano y compasivo». La Proclama del Archiduque Carlos de Austria fue impresa en la imprenta de la Casa de la Misericordia de Cádiz, también a gran formato o formato sábana, y, como la de su hermano el emperador Francisco, fue traducida al español del periódico londinense The Times, que la había publicado el día 22 de abril de 1809.

También, en el Archivo de la Guerra Civil, se conservan otras tres proclamas más, similares a la aludida con anterioridad, de la Junta Suprema Central, redactadas, como secretario de la Junta, por Martín de Garay, en el Real Alcázar de Sevilla e impresas, en 1809, en la Oficina de Nicolás Gómez de Requena, impresor del Gobierno, en Cádiz. La primera de ellas, es la Proclama a los Pueblos de Galicia, de 2 hojas y tamaño cuarto; la segunda, es la proclama por la que la Junta Suprema invitaba a los españoles a celebrar el solemne aniversario por el reposo de las víctimas del dos de Mayo, también de 2 hojas y tamaño cuarto; y, finalmente, la Proclama al pueblo de Cádiz, por un atentado cometido contra un miembro de la Junta Suprema, de 1 hoja de extensión, tamaño 440 × 310 mm. ${ }^{9}$

Finalmente, en el Archivo de la Guerra Civil, se conserva la Proclama del Arzobipo Virey de Nueva España a los fieles vasallos de Fernando VII, impresa, en 1810, en ciudad de México, de 7 folios y tamaño cuarto. Esta Proclama se encuentra reproducida en el segundo tomo de la obra de Juan Hernández Dávalos, Historia de la Guerra de la Independencia de México (México, Imprenta de José M. Sandoval, 1877), que cuenta con una edición facsímil realizada por el Instituto Nacional de Estudios Históricos de la Revolución Mexicana en 1985,

\footnotetext{
${ }_{9}^{9}$ Martín de Garay y Perales (El Puerto de Santa María, Cádiz, 1771-La Almunia de Doña Godina, Zaragoza, 1822) fue secretario de la Junta Suprema de Gobierno del Reino, desde donde desarrolló, también una importante labor diplomática con Inglaterra. De 1810 a 1813, en Cádiz, fue consejero de Estado. Tras la restauración de Fernando VII, en 1816, fue nombrado ministro de Hacienda. Impulsor del Canal Imperial de Aragón, Martín de Garay está enterrado en la iglesia de la Asunción de Nuestra Señora de la Almunia de Doña Godina. Sobre Martín de Garay y su papel durante la Guerra de la Independencia, véase Nuria Alonso Garcés, «Martín de Garay, un político relevante en la Guerra de la Independencia», en Francisco Miranda Rubio (coord.), Congreso Internacional Guerra, sociedad y política, 1808-1814. Volumen II, Navarra, Institución Príncipe de Viana. Universidad de Navarra, 2008, pp. 799-816.
} 
y aparece, también, en el Catálogo de la Colección Lafragua de la Benemérita Universidad Autónoma de Puebla, 1616-1873, publicado por la Universidad Nacional Autónoma de México en 2016. El autor de la Proclama, entonces arzobispo de México y virrey de Nueva España, fue el doctor en derecho civil y canónico, y que, con anterioridad, había sido profesor de la Universidad de Alcalá de Henares y obispo de Teruel, Francisco Javier de Linaza y Beaumont (Arnedo, La Rioja, 1749-Ciudad de México, 1815), tres meses y medio antes de que fuera cesado como cuadragésimo quinto virrey de Nueva España por la Junta Suprema Central de Gobierno y antes de su fallecimiento.

\section{Sentencias judiciales, bandos e instrucciones militares}

Por último, hay que señalar que, en el Archivo de la Guerra Civil, se conserva documentación impresa, de caracter judicial y militar, de la Guerra de la Independencia.

Además de dos pasaportes expedidos para facilitar los viajes por carretera del militar Leandro Bernabeu ${ }^{10}$ y la Instrucción que su Magestad se ha dignado aprobar para el corso terrestre contra los exércitos franceses, de 7 páginas, tamaño folio, impresa por la Junta Suprema Gubernativa del Reino en 1809, en el Archivo, se conserva un Bando, dirigido a todos los gallegos, por Ramón de Castro y Gutiérrez. Teniente General de los Ejércitos de S.M., el Rey Fernadno VII, y la sentencia judicial absolutoria y favorable a Rafael de Sobremonte. La sentencia, de 12 páginas y tamaño cuarto, fue impresa en Cádiz, en 1813, por el impresor José María Guerrero, con el título Conclusion Fiscal en el Proceso Militar formando contra el Excmo. Sr. Marques de Sobre-Monte, como Virrey y Capitan General de las Provincias del Rio de la Plata en los años de 1806 y 1807, y Sentencia definitiva pronunciada por el Consejo de Guerra de Oficiales Generales, celebrado en esta plaza los dias 8, 9, 10 , 11 y 12 del presente mes. En este proceso judicial militar, se juzgó la actuación militar de Rafael de Sobremonte (Sevilla, 1746-Cádiz, 1827), III marqués de Sobremonte, entonces virrey del Río de la Plata, al abandonar la capital, Buenos Aires, en 1806, ante el ataque del ejército inglés. Aunque, como ya se ha dicho, la sentencia le fue favorable y resultó absuelto, su presunta cobardía tuvo consecuencias políticas, siendo sustituido, como virrey del Río de la Plata, por Santiago Antonio María de Liniers.

\section{Conclusiones}

Estos son los principales materiales especiales, de gran valor bibliográfico, que, sobre la Guerra de la Independencia, se custodian en el Archivo General

\footnotetext{
10 Sobre la figura del comandante de infantería Leandro Bernabeu, véase José Antonio PÉREZ JuAn, Centralismo y descentralización. Organización y modelos territoriales en Alicante, 1812 1874, Madrid, Instituto Nacional de Administración Pública, 2005, pp. 353-355.
} 
de la Guerra Civil Española del Centro Documental de la Memoria Histórica de Salamanca.

Aunque no se trate de obras que supongan una novedad, pues existen ejemplares similares de las mismas en otros archivos y bibliotecas españoles, sí que conforman una colección bibliográfica original dentro de un archivo dedicado a la Guerra Civil española.

Con este artículo, se trata de dar a conocer y difundir la existencia de este patrimonio documental, que pone en relación al Centro Documental de la Memoria Histórica con otras bibliotecas españolas en las que se custodian colecciones especialmente relevantes para el estudio de la Guerra de la Independencia como la Biblioteca Central Militar, la Biblioteca del Senado en la que se conserva toda la documentación del general Gómez Arteche, la colección Pérez Guzmán de la Real Academia de la Historia y la Biblioteca Nacional, en la que se encuentra la importantísima colección Gómez Imaz, adquirida en mayo de 1977 y formada por más de 3.000 obras (signaturas $\mathrm{R} / 60001$ a R/63337).

\section{Apéndice}

Listado completo de las obras que conforman los materiales especiales de la época y sobre la Guerra de la Independencia conservados en el Centro Documental de la Memoria Histórica de Salamanca

Proclama que el mariscal de campo D. Gregorio Laguna dirige a su paysanos extremeños. Badajoz, junio de 1808.

GARCÍA DE LA MADRID, Miguel (1783-1839), Representación hecha á las Cortes contra el edicto que se atribuye á nuestro eminentísimo y reverendísimo Arzobispo, dado en Toledo (en donde no residia á la sazón) á 6 de julio próximo pasado, según el Diario de esta Corte de 20 del mismo mes, y en defensa del Artículo 371 de nuestra Constitución. Madrid: Imprenta de Ibarra, 1913. 44 p.; $4^{\circ}$.

EL DesCubridor DEL DuENDE DE NuEstros EJERCITOS (seudónimo), Defensa de la libertad de la imprenta, ó examen del papel intitulado: Observaciones sobre la libertad de la prensa. Isla del León [Cádiz]: Imprenta de Francisco de Paula Periu, 1810. 20 p. [faltan 4 p.]; $4^{\circ}$.

Representación de los ilustrísimos Señores Arzobispo de Tarragona, y Obispos de Lérida, Tortosa, Barcelona, Urgel, Teruel, Pamplona y Cartagena, dirigida á las Cortes Generales y Extraordinarias, en que piden el restablecimiento del Santo Tribunal de la Inquisición al exercicio de sus funciones, [Texto impreso]: leida en la sensión pública del lúnes 18 de mayo. Cádiz: en la Oficina de la Viuda de Comes, 1812. 11 p.; 4.

Manifiesto de la justicia, de la importancia y de la necesidad que halla el Rey Nuestro Señor para oponerse á la agresion del usurpador Bounaparte, procurar el reposo y tranquilidad de la Europa, y proteger los derechos de la bumanidad y de la religion, en alianza y union con

Titivillus, ISSN 2387-0915, ISSN-e 2603-9966, 4 (2018), pp. 165-180 
los soberanos que firmaron en Viena la declaración de 13 de marzo del presente año. Madrid: en la Imprenta Real, 1815. 16 p.; 4.

Exhortacion que la Junta de Armamento de la Ciudad y Provincia de Burgos dirige á sus leales habitantes para que con sus personas y bienes concurran à la defensa de la Religión, de la Patria y del Rey. Burgos, octubre de 1808.

Proclamación del Rey Nuestro Señor D. Fernando Septimo (que Dios guarde) becha en la M. N. y M. M. L. Ciudad de Burgos, cabeza de Castilla, Camara de S.M. y primera de Voto en Cortes, el dia 13 de Noviembre de 1814, que, por el acuerdo del Ilmo. Ayuntamiento de ella, presentan a el público los Comisionados del mismo, para solemnizar aquel acto, D. Josef Bernardo Iñigo de Angúlo, D. Francisco Fernandez de Castro, D. Manuel de Quevedo, y D. Manuel Ignacio Lopez. Burgos: en la Imprenta de Navas, 1814. 78 p.; $4^{\circ}$.

Carta XXVIII del filósofo Rancio: impugnación del informe que la Comisión de Constitución presentó a las Córtes sobre el Tribunal de la Inquisición y del proyecto de decreto acerca de los tribunales protectores de la religión. Cádiz: impreso por D. Antonio de Murguía, 1813. 32 p.; $4^{\circ}$.

TAMARIZ, Mariano, Sentimiento patriotico que en el dia del feliz cumple años en que se instaló la Suprema Junta Central de Gobierno de España e Indias, publicó don Mariano Tamariz, Comisario de Guerra de los Reales Exércitos, Individuo de varias Sociedades del Reyno. Puerto de Santa María [Cádiz]: 1809. 5 p.; 4.

Conclusión Fiscal en el Proceso Militar formado contra el Excmo. Sr. Marques de SobreMonte, como Virrey y Capitan General de las Provincias del Rio de la Plata en los años de 1806 y 1807, y Sentencia definitiva pronunciada por el Consejo de Guerra de Oficiales Generales, celebrado en esta plaza los días 8, 9, 10, 11 y 12 del presente mes. Cádiz: por D. José María Guerrero, 1813. 12 p.; $4^{\circ}$.

Representacion de las damas españolas a Jorge Tercero, Rei de Inglaterra, sobre los vagos rumores acerca de la conducta del Gobierno Ingles y de sus Exércitos en la Guerra de España. Cádiz: Imprenta de Carreño, 1811. 23 p.; $4^{\circ}$.

Proclama de la Junta Suprema de Gobierno del Reyno á los andaluces. Aranjuez [Madrid], 1808.

Proclama del Archiduque Carlos de Austria, hecha en Viena el 6 de abril de 1809. Cádiz: Imprenta de la Casa de la Misericordia, 1809. Tamaño gran formato.

Proclama de S.M. Imperial Francisco I, por la gracia de Dios, emperador de Austria, hecha en Viena el 18 de abril de 1809. Cádiz: Imprenta de la Casa de la Misericorida, 1809. Tamaño gran formato.

Pueblos de Galicia: Al veros caer en poder del enemigo sin resistencia alguna, al contemplar ocupados los emporios navales que ensoberbecen vuestras costas, y dominada de mar á mar tan principal y poderosa Provincia; la indignación y el dolor hicieron prorrumpir á vuestra patria en quejas de madición y de enojo ... [Texto impreso] / Junta Central Gubernativa del Reino de España]. [S.l.] [1809]. 2 h.; $4^{\circ}$. 
Españoles: La Junta Suprema os convida á celebrar con ella en el dia diez y seis de este mes el solemne aniversario que ha decretado por el reposo eterno de las víctimas del dos de Mayo. Honremos en este dia á los fundadores de la libertad, a los que ... [Texto impreso] / Junta Central Gubernativa del Reino de España]. [S.1.] [1809]. 2 h.; 4 .

Proclama al Exercito Español con motivo de la entrada de los prisioneros de Ucles en Madrid. Madrid, enero de 1809.

Proclama del Arzobispo Virey de Nueva España a los fieles vasallos de Fernando VII. Ciudad de México, 1810.

Dictamen de las Comisiones encargadas de informar a las Cortes sobre el restablecimiento y reforma de las Casas Religiosas, mandado imprimir por orden de S.M. Cádiz: Imprenta Nacional, 1813.79 p.; $4^{\circ}$.

La Junta Central Suprema Gubernativa del Reyno al pueblo de Cádiz: En medio de los gravisimos cuidados y de las atenciones tan vastas como importantes que ocupan á la Junta Suprema, un suceso inesperado ha venido á interrumpirlas, y á cubrirle de amargura. Vuestro patriotismo convertido en frenesí, ha desconocido, habitantes de Cádiz, toda subordinación y órden, y ha atentado contra la persona de un Comisionado de la misma Junta, Representante de la Nacion en ella ... [Texto impreso] / [Junta Central Gubernativa del Reino de España]. [Cádiz]: en la Oficina de D. Nicolás Gómez de Requena, Impresor del Gobierno, [1809]. 1 h.; 44 x 31 cm.

OstolazA Y Ríos, Blas de, Los reos de Estado convencidos de haber conspirado á destruir el Gobierno monarquico en España, que da á luz. F.J.G.D.M.A.N. Madrid: por D. Francisco Martínez Villa, 1815.

Gritos de Madrid cautivo á los pueblos de España. Nuevo género de esclavitud que prepara la bondad y amor paternal del Rey Josef á los pueblos que tengan la dicha de caer baxo su benéfica dominacion. Sevilla, 1809. 16 p.; $4^{\circ}$.

Bando, dirigido a todos los gallegos, por Ramón de Castro y Gutiérrez. Teniente General de los Ejércitos de S.M., el Rey Fernadno VII. La Coruña, diciembre de 1809.

OstolazA Y Ríos, Blas de, Sermón patriótico-moral, que con motivo de una misa solemne, mandada celebrar el dia 25 de julio del año 1810 en la iglesia de los RR.PP. Carmelitas de la ciudad de Cádiz por los españoles emigrados de los paises ocupados por el enemigo comun, dixo el doctor don Blas Ostolaza, diputado en Córtes, capellan de honor y confesor de S.M.C. el señor don Fernando Séptimo, rey de España y de sus Indias, y del señor infante don Carlos. Madrid: Imprenta de la Compañía por su regente Juan Josef Siguenza y Vera, 1814. 64 p.; $4^{\circ}$.

La arbitrariedad é injusticia del odio de los filósofos de España á los Institutos Regulares, manifestadas al más justo y grande de los monarcas el Sr. D. Fernando VII, por el mas pequeño, pero el mas afecto de sus vasallos P.J.F.J.R. Manresa [Barcelona]: Imprenta de Abadal, 1813.76 p.; $4^{\circ}$.

Manifiesto de la nación española á la Europa. Sevilla, 1809. 38 p., 1 h. en bl.; 4.

Titivillus, ISSN 2387-0915, ISSN-e 2603-9966, 4 (2018), pp. 165-180 
España vindicada, en sus clases y autoridades, de las falsas opiniones que se la atribuien. Cádiz: En la Imprenta de D. Manuél Bosch, 1811.80 p.; 4.

¿Quál bubiera sido la suerte de España si Fernando VII no bubiera ido a Bayona? Papel, en que se manifiestan las justas causas que obligarian á nuestro Augusto Soberano á pasar á Bayona: bienes que de esto han resultado, y males que se han impedido. P.D.M.L.M.P. [Murcia]: en la Imprenta de la Gaceta de Murcia, 1809. 24 p.; $4^{\circ}$.

Cancion que dedica y dirige a nuestro idolatrado soberano y Sr. D. Fernando VII uno de us mas bumildes y fieles vasallos, tan amante de su patria, que por no faltar un momento el cumplimiento de las obligaciones de su destino militar en defensa de esta plaza, en sus tres asedios, sufrio en el ultimo tantas penalidades, que le produxeron la ruina de su salud. Valencia: Imprenta de Francisco Brusola, 1814. 20 p.; 4.

Ruiz de AlCalá, Antonio, Defensa de D. Miguel de Lardizábal presentada en 4 de mayo de 1812 ante el Tribunal Especial creado por las Córtes Generales y Extraordinarias, por el licenciado Antonio Ruiz de Alcalá. Cádiz: por D. Vicente Lema, 1813. 42 p.; $4^{\circ}$.

Breve noticia del contesto de los Contrafueros y Leyes sancionadas en las presentes Cortes de los años 1817 y 1818. Pamplona: Imprenta de Longás, [1818]. 11 p.; Tamaño folio.

Argüelles como es en sí: su sabiduría, su piedad, su verdadero amor á la iglesia C.A.R... cu todo contra los egoístas, déspotas, usurpadores (y añadamos por si acaso) y contra los ignorantes preocupados por F.M.G.N. Cádiz: por D. Vicente Lema, 1814. 40 p.; 4 .

Instrucción que su Magestad se ha dignado aprobar para el coros terrestre contra los exércitos franceses. Sevilla, 1809. 7 p.; Tamaño folio.

Correspondencia de los generales Castaños y Cuesta, y del Consejo Real sobre la prisión del Excmo. Sr. Baylio Fr. D. Antonio Valdés y Bazán. Sevilla: en la Imprenta de la Viuda de Hidalgo y sobrino, 1808. 20 p.; Tamaño folio.

Nos don Ramón Josef de Arce, por la gracia de Dios y de la Santa Sede Apostólica, Arzobispo de Burgos, del Consejo de S.M., Caballero de la Gran Cruz de la Real Orden de Cárlos III, é Inquisidor general en todos los Reynos y Señorios de S.M. a todos los Fieles habitantes ó moradores de ellos, de qualquier estado, calidad, órden, ó dignidad que sean: Hacemos saber, que por nuestro Santisimo Padre Pio VI, de gloriosa memoria, manifestando su santo zelo por la pureza de la fe, pazy tranquilidad del pueblo christiano, se expidieron unas Letras en forma de Breve que S.M. el Señor Càrlos IV (que Dios guarde), uniendo sus religiosas intenciones á las de S.B., se ha servido comunicarnos, y son el tenor siguiente. [S.1.], 1801. 48 p.; Tamaño folio.

Ordenanzas dispuestas por la Diputación de la Real Sociedad de la Rioja Castellana, para la conservacion de los caminos, plantios y demas objetos puestos à su cuidado, con aprobacion de S.M. Logroño: por Antonio Joseph Delgado, Impresor de la Sociedad, 1799. 73 p.; $4^{\circ}$.

Concesión de pasaporte al Subteniente Leandro Bernabeu. Pamplona, 1834.

Titivillus, ISSN 2387-0915, ISSN-e 2603-9966, 4 (2018), pp. 165-180 
Concesión de pasaporte al Comandante de Infantería Leandro Bernabeu. Madrid, 1838.

Núm. 22. Apéndice al Procurador General de la Nacion y del Rey. Señor Procurador de la Nacion y del Rey, sirvase vmd. Insertar en su periódico el adjunto dictamen que debi haber leído en la discusión que terminó el 23 del presente, y el qual no tuvo lugar porque se declaró discutida la materia, á pesar de que teniamos pedida la palabra mas de doce diputados: inserte vmd. Igualmente lo que iba á decir el 26 del presente, despues que habló el Sr. Calatraba, y lo que bice, porque sucedió en esta votación lo que en la otra; estaba pues esperando á decir poco mas ó menos lo siguiente. Señor. Si se trata de examinar la qüestion que ha propuesto el Señor Creux, á saber: si el Consejo Supremo de Inquición tiene ó no expedita la jurisdiccion Pontificia que le está delegada... Cádiz: Imprenta de D. José Niel, 1813. 44 p.; $4^{\circ}$.

Excelentísimo Señor: Despues de la defensa del Estado, que ha sido el primer objeto de las atenciones de la Junta Suprema, á nada se ha aplicado mas que á conservar la unión y la concordia entre las diversas partes que constituyen la Monarquia, y entre las diferentes autoridades que la dirigen y gobiernan. Sevilla, 1809. 22 p.; $4^{\circ}$.

Apuntes de la vida y hechos militares del brigadier don Juan Martín Diez, «el Empecinado», por un admirador de ellos. Madrid: Imprenta de Fermín Villalpando, 1814. 91 p.; $4^{\circ}$.

Papeles varios. Tortosa [Tarragona], 1811-1818. 339 folios.

Papeles varios. [S.1.], 1701-1717. 421 folios. 